\title{
A SOCIOLOGIA DE PIERRE BOURDIEU (OU COMO UM AUTOR SE TORNA INDISPENSÁVEL AO NOSSO REGIME DE LEITURAS)
}

\begin{abstract}
Afrânio Mendes Catani"
Dos meus companheiros de classe, alguns finos como corais, poucos assinam hoje o nome. A mão amoldou-se de tal maneira ao cabo da enxada, foi tanta a negrura e a fome que os rodeou, que esqueceram de todo que havia letras e pensamento. Mogadouro, Montezinho, Nogueira, Bornes, Padrela (Ainda me lembro ) ( ). E doeu-me só eu ter tido coragem de abrir os olhos contra quem mos queria mergulhados em terra de servidão.
\end{abstract}

Miguel Torga (Diário III, 1946)

RESUMO: O artigo recupera momentos da trajetória de investigação de Bourdieu, procurando mostrar como suas obras foram incorporadas a meu regime de leituras. Com tal postura espero contribuir para que os pressupostos teóricos desse pensador se difundam entre os envolvidos com vertente significativa da sociologia contemporânea.

Palavras-chave: Pierre Bourdieu. Sociologia. Regime de leituras. Trajetória de pesquisa. Exclusão social.

\section{Pierre Bourdieu's Sociology (OR HOW AN AUTHOR BECOMES ESSENTIAL TO OUR READINGS)}

ABSTRACT: This paper intends to rescue some moments of Bourdieu's research pathway, in an attempt to show how his work integrated my readings. From this perspective, I hope to contribute to disseminate Bourdieu's theoretical standpoints among those who are concerned with this valuable tendency in contemporary Sociology.

Key words: Pierre Bourdieu; Sociology; readings; research pathway; social exclusion.

\footnotetext{
* Meus agradecimentos a Paula Perin Vicentini, a Claire e a Antoine Li, a Renato de Sousa Porto Gilioli.

* Professor na Faculdade de Educação da Universidade de São Paulo e no Programa de PósGraduação em Integração da América Latina (Prolam) da USP. E-mail: amcatani@usp.br.
} 
que significa dizer que um autor se torna indispensável ao nosso regime de leituras? Em essência, indica que ele ingressa em nosso sistema de pensamento da mesma forma que Horacio González entende que Walter Benjamin é imprescindível para que se possa dar continuidade a um determinado projeto acadêmico, ou seja, penetra aos pedaços,

através de fendas no tempo, quando estamos distraídos ou em ocasiões em que um livro puxa outro numa cadeia, que só pode se estabelecer se nosso interesse se mantém vivo ou se esses livros estão à mão. Podemos acrescentar: com certos autores nos detemos sempre em um lugar, em um trecho, em certa página. E se avançamos, pode ocorrer que tenhamos a impressão de que já havíamos passado por ali. (González, 1992, p. 167)

Ainda falando de Benjamin - mas desenvolvendo propriedades que podem ser atribuídas a Bourdieu -, González escreve que o autor

relaciona objetos diferentes no vôo, para produzir novos conceitos ( ). Pensar é unir o diferente ao vôo. Ou, o que é a mesma coisa, pensar é converter o atmosférico no intelectual, o maiúsculo no minúsculo, o fragmentário no histórico, o técnico no profético e o revolucionário em um ato de memória involuntário. (Idem, p. 169).

Assim, quem ler as linhas a seguir talvez perceba o esforço desenvolvido para fazer falar a um autor, como o faz Bourdieu quando discute a obra, as leituras, em suma, a inserção no campo intelectual francês (e mundial) de Foucault. Escreve que

deve-se distinguir entre os leitores, os comentadores, que lêem para falar em seguida do que se leu; e os que lêem para fazer algo, para fazer avançar o conhecimento, os autores ( ). Uma leitura deleitor que quer compreender realmente a Foucault enquanto autor, enquanto criador do pensamento dos outros ( ), não deveria, esta leitura, ir mais além da leitura dos textos? ( ) Para compreender uma obra deve-se compreender inicialmente a produção, o campo da produção; a relação entre o campo no qual ela se produz e o campo em que a obra é recebida ou, mais precisamente, a relação entre as posições do autor e do leitor em seus respectivos campos. (Bourdieu, 1997, p. 13)

Pode-se aplicar ao próprio Bourdieu os juízos aplicados a Foucault quanto ao 'entendimento' de sua obra:

( ) para entender a 'recepção' [de um autor] deve-se entender as forças da não recepção, a recusa em saber, o 'ódio pela verdade', a respeito do qual Pascal fala em algum lugar. Sartre, em uma nota de $A$ crítica da razão dialética, disse, a propósito de suas leituras juvenis de Marx (que não se lia na universidade): 'eu 
compreendia tudo e não compreendia nada'. Quer dizer que há uma compreensão (escolar em geral) que é uma não compreensão, um fazer como se se compreendera, uma falta de compreensão fundada em resistências profundas. (Idem, p. 19)

Estudando a temática das condições de recepção da obra de Bourdieu nos Estados Unidos, L. Wacquant afirma:

se é verdade que o sentido de uma obra (artística, literária, filosófica etc.) muda automaticamente a cada mudança no campo em que está situada para o expectador ou leitor, então a adequada compreensão de um determinado autor impõe um duplo trabalho de elucidação: de suas idéias e do universo intelectual no qual elas chegam a circular. Requer que codifiquemos o espaço mental do autor - isto é, as categorias e postulados que o sustentam ou sua maneira de pensar e teorias substantivas - e requer, também, que consigamos alguma informação acerca do espaço acadêmico no qual seus escritos estão inseridos. (Wacquant, 1993, p. 235)

Para o caso brasileiro, ver Cunha (1982), Durand (1982), Silva (1986) e Catani, Catani, Pereira (2001c).

Então, ao invés de tratamento sistemático e didático de toda a obra de Bourdieu e suas condições de recepção, tem-se considerações sobre o percurso intelectual do autor e de como, a partir de minha formação, seus trabalhos se integraram ao meu regime de leituras, tornando-se quase impossível seguir sem ele na realização da modalidade de trabalho simbólico ao qual me dedico. É dizer: é um artigo propositadamente ao estilo de um vagão de cargas, com parafusos à mostra, em que surgem hesitações e incompletudes, mas em que se encontram também alguns passos decisivos que me ajudaram a investir parte de minhas energias para que me convertesse, talvez, em um autor. Quem sabe isso seja de alguma valia. Porém, como esses passos foram dados ao longo de vários anos, convém lembrar uma vez mais a advertência de Jorge Luis Borges, em Milonga de Albornoz: "el tiempo es olvido y es memoria”.

Nascido no interior do estado de São Paulo no início dos anos 50, aos 6 anos ingressei no grupo escolar (1960). Cabe acrescentar: grupo escolar público, classes de 40 alunos, carteiras duplas, com buraco para se colocar o tinteiro no meio, fileiras com cinco carteiras e um professor por classe ministrando aulas de segunda a sábado, das 8 às 11 horas. A clientela era eclética, com quase todos os segmentos sociais representados: exceto pouco mais de dez alunos, as turmas tinham filhos de famílias modestas, operários, empregados no comércio, bancos e funcionários 
públicos em início de carreira. Eu era típico representante desses pouco mais de dez alunos, em cujas casas havia biblioteca e até máquina de escrever - além de receber diariamente um jornal da capital e outro do interior. Vários colegas trabalhavam a partir do meio-dia e crianças negras eram quase metade da sala. Alguns desses meninos que já trabalhavam eram inteligentíssimos, executavam com facilidade operações aritméticas, formulavam frases que envolviam articulações complexas e freqüentemente nos passavam a perna quando o assunto referia-se a qualquer malandragem (atirar papel em outro aluno, soltar pum, fazer um gracejo qualquer ) e tínhamos de nos haver com o(a) professor(a): sempre a punição sobrava para "os filhos de gente de bem" (Catani, 1998).

Terminei o primário em 1963 e, no ano seguinte, após ser aprovado no antigo exame de admissão, ingressei no curso ginasial. Acredito que mais de 30 de meus antigos colegas de classe não seguiram em seus estudos: foram obrigados a prosseguir nas atividades às quais já se dedicavam, obtendo pequenas promoções (haviam passado a trabalhar a jornada completa) que representavam modestos acréscimos nos seus parcos salários. Quando completei o ginásio e me preparava para ingressar no científico, através de outra seleção, era possível encontrar Jurandir e seu irmão Anésio cuidando da faxina de um cinema modesto no centro da cidade (em algumas noites, encarregava-se da bonbonnière); Josué fazia entregas para uma mercearia do meu bairro; João Batista ajudava o pai a vender, nos fins de semana e em parques de diversões, sorvetes coloridos que instantaneamente deixavam o estado líquido e se materializavam em casquinhas; Lázaro Izidoro vendia, aos sábados e domingos, pipocas saltitantes com o Sr. Lázaro; Orlando, na boléia da charrete, transportava lenha que recolhia pela cidade; Durval e Paulino eram office-boys de escritórios de contabilidade, ao passo que Benedito era balconista em uma loja de tecidos. Confesso que já aos dez ou onze anos ficava fascinado e, com certeza, achava bem mais interessante o exercício dessas atividades do que ficar sentado estudando, copiando, brigando ingloriamente com as linhas do caderno de caligrafia, decorando nomes de ramais ferroviários ou resolvendo problemas de aritmética. A virulência contra essa espécie de utopia de não-aprendizagem escolar, contra a tentativa de que gazeteássemos, não era moderada, sendo desencadeada com eficácia por parte de nossos pais e dos familiares dos colegas que não necessitavam trabalhar para "ajudar em casa".

Não me dava conta, na época, da exclusão das oportunidades a que meus colegas de classe estavam sujeitos. Intuitivamente, ia entendendo 
as regras que permitem a alguns obter a progressão no sistema de ensino (e em seu destino), enquanto aos demais se reservava o trabalho duro, em geral repetitivo e mal remunerado. Anos mais tarde, após deixar a casa paterna aos 17 anos, ser obrigado a "ganhar a vida" e, necessariamente, ter que me resituar frente a todo um universo familiar que já se me apresentava como tendo pouco significado e, em especial, frente ao universo estudantil, com suas múltiplas possibilidades, creio ter percebido em sua plenitude os mecanismos de exclusão a que me referi. Em 1972, comecei a trabalhar com Sergio Miceli, acentuando-se a possibilidade de entender minha própria situação, através das leituras iniciais de Bourdieu. Foi um choque, pois os textos eram, para um jovem provinciano chegado há não muito em São Paulo, dificílimos. O primeiro texto de Bourdieu lido foi a versão castelhana de Les héritiers: Les étudiants et la culture (1964), editada com o título Los estudiantes y la cultura (Barcelona: Editorial Labor, 2a ed., 1969 - tradução: María Teresa López Pardina; prólogo: José Luis L. Aranguren), que fora adquirida em 1971 pela biblioteca da Fundação Getúlio Vargas, onde cursava Administração Pública, trabalhava e militava. Atônito, percebi que este pequeno livro fornecia o caminho teórico a ser seguido para entender aquilo que Bourdieu escreveria com todas as letras, anos depois, isto é, que a sociologia toca, na maioria das vezes, em "interesses vitais" e, nesse sentido, "revela os fundamentos ocultos desta dominação.” (Questões de Sociologia, p. 7).

Reolhando os anos que marcaram o fim de meu antigo curso científico, a realização do "cursinho" e o posterior ingresso no ensino superior, percebia o desconforto que enfrentava ao comparar minha situação com a dos primos que estudavam na capital paulista: embora estivesse no top, num dos melhores colégios públicos da cidade interiorana em que vivia, com o destino teoricamente bem encaminhado se comparado ao da maioria dos jovens que haviam compartilhado os bancos escolares comigo, me sentia um total ignorante frente a Fernando, a José Ignácio e a outros primos de primos, que tinham realizado toda a trajetória escolar, até então, em São Paulo. Enquanto, por exemplo, o Padre Charbonneau lecionava Filosofia e discutia As palavras (Sartre) e o existencialismo, no Colégio Santa Cruz, nós tínhamos, no Colégio Estadual e Escola Normal Monsenhor Jerônimo Gallo, um péssimo professor que nos obrigava a comprar a apostila de sua autoria e a ler, em duas ou três páginas, o pensamento de José Ingenieros. História, Literatura (brasileira e portuguesa), leituras avançadas em Inglês, dentre outras, integravam o cotidiano de estudos dos jovens paulistanos dos colégios particulares de elite, enquanto estudávamos apenas as matérias 
“que contavam” para o vestibular em exatas e biológicas: Física, Química, Biologia, Matemática (além de rudimentos de Inglês, a já mencionada Filosofia e mais alguma disciplina que não me lembro). De uma classe de 36 alunos do $3^{\circ}$ científico diurno fui o único que se dirigiu às humanidades, sem a formação necessária para enfrentar um vestibular em que a concorrência era forte, obrigando-me a um esforço descomunal, ao longo de 125 dias, para obter aprovação simplesmente discreta (o que para mim foi uma maravilha): na classificação fui o sexto da lista, de baixo para cima

Sergio Miceli escreveu que Bourdieu reiterou obsessivamente ao longo de sua obra os ganhos heurísticos dessa experiência cruzada entre o "desenraizamento de um universo familiar" e a "familiarização com um universo estrangeiro" (Miceli, 1999). Por ocasião da morte de Bourdieu, Jean-François Dortier ponderou, em artigo de abertura de número especial dedicado ao sociólogo, que

as grandes obras nascem sempre de uma experiência fundadora, de um traumatismo, de uma tensão interior. O pensamento de Bourdieu crava suas raízes em uma dolorosa experiência existencial. Ela remonta a sua adolescência, a sua entrada no Liceu Louis-le-Grand, depois na prestigiosa École Normale Supérieure, rua d’Ulm, na qual ingressa em 1951. (Dortier, 2002, p. 3)

Acrescenta que o jovem provinciano, "de esquerda e desajeitado", encontra-se imerso num mundo que não é o seu:

um mundo de jovens burgueses, brilhantes, bem falantes, cultos, tão à vontade no manejo da fala quanto da escrita. Se o jovem Bourdieu foi bem-sucedido ao galgar todos os escalões da hierarquia escolar, não o foi pela desenvoltura, nem pela escrita, nem pelos arroubos oratórios. E nem o será jamais. Embora sua obra escrita seja imponente, ele não irá possuir a escrita fácil e alerta; mesmo tendo feito centenas de conferências, não será um orador. Como Flaubert, a quem consagra $A$ s regras da arte. Gênese e estrutura do campo literário (Seuil, 1992), a expressão de seu pensamento deve passar pelo esforço permanente de auto-controle, pela luta contra si mesmo. Exatamente o contrário da aparente desenvoltura de seus estudantes oriundos da burguesia culta que ele encontra na rua d'Ulm. Desde a infância eles foram banhados no universo da cultura erudita. Bem precocemente, eles manipularam os livros, freqüentavam os museus, viajaram, assistiram às conversações nas quais se sabia falar, argumentar, em que as palavras e as idéias voam, fundem-se, onde o espírito é rei. Esses herdeiros adquirem essas disposições para falar e pensar, sem esforço aparente. Em Ce que parler veut dire (Arthème-Fayard, 1982), Bourdieu se dedicará a destrinçar a maneira pela qual o manejo da linguagem se revela um instrumento de poder, de poder simbólico. (Dortier, 2002, p. 3-4) 
E avança de maneira significativa nessa vertente interpretativa, escrevendo que em determinada sociedade, quem não detém as chaves para a manipulação da linguagem é fisicamente

\begin{abstract}
posto em posição de inferioridade, pelo medo, pela algaravia, pelo sotaque, que fazem com que ele seja notado quando comece a falar. Imersos num meio no qual se sabe manejar a palavra, onde a língua culta é a língua natural, esses jovens integram desde a infância as regras do saber-viver intelectual e do saberpensar. Essa elite estudantil será descrita por Bourdieu em Lés Héritiers (Minuit, 1964) - Os Herdeiros. Esses estudantes privilegiados recebem como herança um bem tão precioso quanto invisível ao olho nu: a cultura. No seio dessa elite intelectual, os valores não são transmitidos pelo dinheiro (o 'capital econômico'), mas pela escola (o 'capital cultural'). ( ) Os melhores elementos dessa casta social estão destinados a seguir o percurso ideal das grandes escolas (Politécnica, Escolas normais superiores, Escola Nacional de Administração) para integrar os grandes órgãos do Estado. Bourdieu lhes consagrará um de seus outros grandes livros: La Noblesse d'État (Minuit, 1989). (Idem, 2002, p. 4)
\end{abstract}

Cabe destacar o que Dortier chamou, em linhas anteriores, a dolorosa experiência existencial de Bourdieu, remontando à adolescência e sua entrada no Liceu Louis-le-Grand. Mas voltemos ao início dos anos 40, quando ele tinha apenas 11 anos e passa a ser aluno interno no Liceu de Pau, principal cidade dos Pirineus Atlânticos (no Béarn), de 1941 a 1947. Entre outubro e dezembro de 2001, quando estava hospitalizado, na fase terminal de sua doença, escreveu uma pequena obra autobiográfica, com cerca de 60 páginas, intitulada Esquisse de socioanalyse. Enviou o manuscrito ao amigo e jornalista Didier Eribon, do Le Nouvel Observateur, que fez, ao longo de 22 anos, muitas entrevistas com o sociólogo e era um de seus leitores privilegiados, a quem Bourdieu remetia originais solicitando críticas e sugestões (inclusive nesse texto, Eribon realizou várias observações, algumas delas prontamente acatadas por Bourdieu). Por ocasião da morte do professor do Collège de France, em 23 de janeiro de 2002, Le Nouvel Observateur ( $n^{\circ}$ 1943, 31/1 a 6/2/ 2002) publicou (p. 46-47) extratos dessa autobiografia, fornecida por Eribon, como homenagem ao autor. Entretanto, a família de Bourdieu, irritada com os artigos que precederam ao dossier, escritos por Françoise Giraud, Jean Daniel e, principalmente, por Jacques Julliard (intitulado "Miséria da sociologia"), decidiu atacar a revista, tentando processá-la por "violação do direito moral", uma vez que não se havia qualquer autorização para divulgar o texto, no todo ou em parte (Alain Salles, Une polémique oppose la famille de P. Bourdieu au 'Nouvel Observateur', Le Monde, 9 fev. 2002). A matéria informava ainda que o texto redigido 
no hospital deveria sair sob a forma de livro, de início, na Alemanha, pela editora Suhrkamp, no mais tardar em junho de 2002. Em Livres Hebdo (8/2/2002), Eribon lamentou o ocorrido e explicou que a divulgação dos extratos foi a forma encontrada para que partes do texto de um "livro incandescente" chegassem logo ao público.

O título que Le Nouvel Observateur deu ao extrato da obra foi "J'avais 15 ans: Pierre par Bourdieu" ("Eu tinha 15 anos: Pierre por Bourdieu”), em que narra sua experiência no internato. Fala da infelicidade de ficar alojado num velho e frio edifício do século XVII, enfrentando a ausência quase total de privacidade, tendo que lutar o tempo todo por coisas insignificantes (chegar na hora certa para o banho, sentar-se antes à mesa de oito lugares do refeitório, lavar os lenços melados às escondidas) e numa convivência difícil com os colegas. Linhas também são dedicadas aos embates cotidianos com os agentes disciplinares (inspetores de alojamento, vigilantes), às punições, delações e pressões para que os internos confessassem que haviam cometido qualquer infração. Estima Bourdieu que, em sua vida escolar, tenha recebido mais de 300 advertências ou punições. Uma das poucas lembranças positivas eram as bagunças (evocadas pelos colegas como "memoráveis") que aprontavam, sendo que muitos deles viviam num "estado próximo de uma espécie de delinqüência". Chegou um momento em que não tinha com quem falar de suas angústias, dúvidas e inquietações. Nos poucos fins de semana quando podia deixar o internato e tentava conversar com os pais, entendia que o culpavam por eventual fracasso escolar: praticamente o consideravam um privilegiado, pois seu pai deixou a escola aos 14 anos, enquanto a mãe saiu aos 16 - o pai era modesto funcionário dos correios. "No inverno, à noite, empilhávamos todas as nossas roupas sobre a cama, para sentirmos um pouco menos de frio".

Bourdieu explora também as diferenças entre os internos e os alunos que apenas freqüentavam as aulas e moravam em Pau e cercanias: a distinção dava o tom em termos de vestuário, sotaque, posturas corporais, quase se configurando um racismo de classe - acrescente-se ainda que alguns professores se deixavam seduzir pelas distinções de classe existentes entre os alunos do Liceu. Disse que reencontraria todas essa situação anos depois, na Khâgne ${ }^{1}$ do Liceu Louis-le-Grand, num combate surdo entre os internos provincianos e os externos parisienses (permaneceu nessa instituição de 1948 a 1951).

Quanto aos seus amigos internos, creio que nos lembram os pequenos colegas de Miguel Torga, descritos na epígrafe do presente artigo: oriundos de pequenas comunidades rurais, filhos de artesãos e 
pequenos comerciantes, se perderam com certa rapidez ao longo do curso, no Liceu. Duas citações refletem bem como Bourdieu vivenciou essa experiência: 1. "Para dar uma idéia poderia, invocando Goffman de 'Asilos', rememorar que o internato não é separado, na série das 'instituições totais', de instâncias como a prisão ou o hospital psiquiátrico ou, mais próximo, da colônia penitenciária tal como a evoca Jean Genet em 'Miracle de la rose', do que por uma diferença de grau"; 2. "Vivi minha vida de interno numa espécie de fúria empedernida".

É justamente em Os herdeiros (escrito com J.-C. Passeron) que Bourdieu mostra claramente que

a experiência do futuro escolar não pode ser a mesma para o filho de um executivo de nível superior que, tendo tido mais de uma chance sobre duas de ir para a faculdade, encontra necessariamente em seu entorno social, e mesmo em sua família, os estudos superiores como um destino banal e cotidiano, e para os filhos de um operário que, tendo menos de duas chances sobre cem de ascender, só conhece o estudos e os estudantes através de outras pessoas e por meios indiretos. (P. 12, grifos do original)

Nesse sentido, a cultura legítima, referendada pelos exames e diplomas, vem a ser aquela pertencente às classes privilegiadas. $\mathrm{O}$ ensino pressupõe implicitamente "um corpo de saberes, de saber-fazer e, principalmente, de saber-dizer, que constitui o patrimônio das classes cultivadas” (p. 36). Assim, o que se estabelece como dom natural constituise geralmente em manifestação de afinidades ligadas a valores sociais bem determinados e às exigências do sistema escolar. No limite, o privilégio social e as habilidades adquiridas na família burguesa travestem-se em méritos individuais, “dons naturais” que o indivíduo possui. Logo, "para os filhos de camponeses, de operários, de empregados ou de pequenos comerciantes, a cultura escolar é aculturação" (Les héritiers, p. 37).

Bourdieu e Passeron denunciam a escola como parte do conjunto de instituições que zelam pela estratificação social numa dada sociedade, colocando "em questão a fraseologia igualitária com que se exprimia a pedagogia liberal” (Prado Jr., 1980, p. 20). O filósofo brasileiro, um dos leitores mais argutos das obras dos sociólogos franceses no Brasil, comenta que é em $A$ reprodução (1970) que esse círculo interpretativo do sistema de ensino enquanto chancelador das diferenças é fechado. No seu entender, o ensino universitário (como os outros) dava o seu $O K$ quanto

às diferenças culturais e lingüísticas já dadas, antes da escolarização, no quadro da socialização primeira, que é necessariamente diferencial, segundo a inscrição 
das famílias nas diferentes classes sociais. É inegável, por exemplo, para insistir no eixo do livro, que o código lingüístico da burguesia (com seus cacoetes, seus idiotismos, enfim, sua particularidade) será reencontrado, pelos futuros notáveis, nas salas de aula, como a linguagem da razão, da cultura, numa palavra, como 'elemento' ou horizonte da Verdade (com V maiúsculo). O particular é arbitrariamente erigido em universal e o 'capital cultural' adquirido na esfera doméstica, pelos filhos da burguesia, lhes assegura um privilégio considerável no destino escolar e profissional. No Destino, enfim. (Idem, p. 21)

No entender de Bourdieu e Passeron, a escola seria a via real da democratização da cultura

se ela não consagrasse, ignorando-as, as desigualdades iniciais diante da cultura e se ela não chegasse freqüentemente - censurando por exemplo a um trabalho escolar por ser muito 'escolar' - a desvalorizar a cultura que ela transmite em proveito da cultura herdada, que não traz a marca plebéia do esforço e tem, por essa razão, todas as aparências da facilidade e da graça. (Les héritiers, p. 35)

Dois anos após Os herdeiros e quatro anos antes de $A$ reprodução (1970), portanto em 1966, Bourdieu publicou na Revue Française de Sociologie o artigo "A escola conservadora: As desigualdades frente à escola e à cultura”. Nogueira e Catani escreveram que tal artigo

assinalou uma etapa decisiva na exploração das funções escolares de reprodução cultural e de conservação social. Rompendo com as explicações fundadas em aptidões naturais e individuais e ensejando - de modo praticamente pioneiro a crítica do mito do 'dom', o autor desvenda as condições sociais e culturais que permitiram o desenvolvimento desse mito. (1998, p. 9)

Acrescentávamos que também desmontavam os mecanismos pelos quais "o sistema de ensino transforma as diferenças iniciais - resultado da transmissão familiar da herança cultural - em desigualdade de destino escolar" (1998, p. 9), recuperando, portanto, muito do que já havia trabalhado com Passeron em 1964. No primeiro parágrafo de seu artigo, escreve que

é provável, por um efeito de inércia cultural, que continuamos tomando o sistema escolar como um fator de mobilidade social, segundo a ideologia da 'escola libertadora', quando, ao contrário, tudo tende a mostrar que ele é um dos fatores mais eficazes de conservação social, pois fornece a aparência de legitimidade às desigualdades sociais, e sanciona a herança cultural e o dom social tratado como dom natural. (Bourdieu, 1998, p. 41)

São dados passos significativos na elaboração de uma teoria do funcionamento e das funções sociais do sistema escolar. Reconhece-se a 
existência de uma distribuição desigual, entre as classes sociais, de um equipamento necessário à apropriação e consumo dos bens culturais, tornando ilusório o discurso (e, portanto, discriminatória a prática) escolar do igualitarismo formal. Esse equipamento pode ser entendido como a "herança cultural", composta de "um capital de informação, de saberes, de usos lingüísticos, mas também de atitudes e de posturas" (Nogueira, 1989, p. 4).

A escola, ao ignorar desigualdades culturais entre crianças de diferentes classes sociais ao transmitir os conteúdos que opera, bem como seus métodos e técnicas e os critérios de avaliação que utiliza, favorece os mais favorecidos e desfavorece os mais desfavorecidos. "Em outras palavras, tratando todos os educandos, por mais desiguais que sejam eles de fato, como iguais em direitos e deveres, o sistema escolar é levado a dar sua sanção às desigualdades iniciais diante da cultura" (Bourdieu, 1998, p. 53).

M. A. Nogueira ressalta que é em 'A escola conservadora' que à noção de "ethos de classe" - "que se poderia definir como o resultado do processo pelo qual os diferentes grupos sociais interiorizam sua situação objetiva, em matéria de probabilidades educacionais, transmutando-a em aspirações, desejos, etc. subjetivos” - iria se acrescentar, posteriormente, o conceito de babitus ("esquemas estruturados de percepção, pensamento, ação, formados a partir dos modos de viver e de pensar das diferentes classes sociais, e que se traduzem por predisposições ou disposições duráveis em direção à ação”), na análise da ação pedagógica como imposição de uma arbitrário cultural” (Nogueira, 1989, p. 4). ${ }^{4}$

O conceito de habitus aparece pela primeira vez nos escritos de Bourdieu em $A$ reprodução. Depois, é rediscutido amplamente em seu outro livro, Esquisse d'une théorie de la pratique (1972), além de ter sido trabalhado em dezenas de artigos e também em livros publicados posteriormente. Gosto, em especial, de uma interpretação de Sergio Miceli em que o habitus é entendido como

um conjunto de padrões de comportamento, pensamento e gosto, com 'traduções' nos diferentes domínios da prática, que acaba operando um ligamento entre a força do 'coletivo' e os registros caprichosos das práticas individuais. A 'interdependência' entre os integrantes dos diversos agrupamentos sociais garantiria a circulação de constrangimentos, fazendo ver ao homem mais humilde os fundamentos sociais dos privilégios dos poderosos e, vive-versa, não poupando sequer os dirigentes mais arrogantes de algum sentimento de responsabilidade pelas condições de pobreza e violência entre os miseráveis. (Miceli, 1997). ${ }^{5}$ 
Explora-se também, em 'A escola conservadora', a relação com o saber (em detrimento do saber em si mesmo), sendo que tal relação constitui-se em uma das características principais da teoria de Bourdieu. Os educandos oriundos de famílias desprovidas de capital cultural apresentarão uma relação com as obras de cultura veiculadas pela escola que tende a ser interessada, laboriosa, tensa, esforçada, enquanto para os indivíduos originários de meios culturalmente privilegiados essa relação está marcada pelo diletantismo, desenvoltura, elegância, facilidade verbal "natural". Ao avaliar o desempenho dos alunos, a escola leva em conta, sobretudo (conscientemente ou não), esse modo de aquisição (e uso) do saber - em outros termos, essa relação com o saber (Nogueira \& Catani, 1998, p. 9). Bourdieu \& Saint-Martin, em As categorias do juízo professoral, originalmente publicado em 1975, constatam que nada escapa ao julgamento operado pelo docente na hora de avaliar o produto do trabalho discente. Juntamente com os "critérios internos" de avaliação de um dado tipo de conhecimento (domínio do campo, vocabulário técnico, entre outros), levam-se em conta, sobretudo, "critérios externos" (postura corporal, maneiras, aparência física, dicção, sotaque, estilo da linguagem oral e escrita, cultura geral etc.). Desnudam o sistema de classificação que orienta a apreciação do mestre e que se expressa através de uma "taxionomia propriamente escolar" que distingue - e opõe qualidades superiores como brilho, originalidade, fineza, sutileza, elegância, desenvoltura, de virtudes inferiores (ou até mesmo "negativas") como esforço, seriedade, precisão, modéstia, correção (Bourdieu \& SaintMartin, 1998; Nogueira \& Catani, 1998, p. 12-13; Catani, 2002).

A reprodução: Elementos para uma teoria do ensino não me fascinou na ocasião. Talvez o livro 1 (Fundamentos de uma teoria da violência simbólica) seja um dos escritos mais cacetes que li, apesar de sua relevância. Tive contato com o texto em 1972. Nesta parte da obra, articulam-se conceitos-chave explorados com maestria: violência simbólica, babitus, prática, ação pedagógica, autoridade pedagógica, arbitrário cultural, trabalho pedagógico, modos (de aquisição, imposição, inculcação), reprodução (cultural e social)

Por sua vez, o livro 2 (A manutenção da ordem) é fundamental para qualquer pessoa dedicada ao pensar e, como ponderou Prado Jr. (1980), é aí que esse círculo interpretativo do sistema de ensino enquanto chancelador das diferenças se fecha. Carregando nas tintas, pode-se dizer que esta parte pode ser lida quase que independentemente. A epígrafe geral do livro 2 é uma passagem emprestada de Por que professores?, de Gusdorf: "A função docente tem, por conseguinte, a missão de manter e 
promover essa ordem nos pensamentos, tão necessária quanto a ordem na rua e nas províncias”. A seguir, encontram-se capítulos decisivos para uma sociologia que procura fazer com que a revelação dos "fundamentos ocultos da dominação" constitua-se em conhecimento - e o conhecimento exerce um efeito libertador, pois tais mecanismos devem parte considerável de sua eficácia ao desconhecimento, por parte dos agentes, de sua real situação. Basta olhar os títulos dos 4 capítulos da parte 2 para constatar isso: 1. Capital cultural e comunicação pedagógica; 2. Tradição erudita e conservação social; 3. Eliminação e seleção; 4. A dependência pela independência. Já as epígrafes de Pascal e de Marx foram bem escolhidas, ilustrando os conteúdos desses capítulos. Nos Pensamentos, Pascal escreveu:

Nossos magistrados conheceram bem esse mistério. Suas togas vermelhas, as peles de arminho em que se envolvem, os palácios onde julgam, todo esse aparato augusto era muito necessário; e se os médicos não tivessem sotainas e galochas e se os doutores não usassem barretes e roupas muito amplas, jamais teriam iludido o mundo que não pode resistir a essa gala tão autêntica. Os militares são os únicos a não disfarçar sua condição, porque, com efeito, sua parte é mais essencial: eles se organizam pela força, os outros pelo fingimento. (Capítulo 2)

Marx, por sua vez, é citado em "Eliminação e seleção": "O exame não é outra coisa senão o batismo burocrático do conhecimento, o reconhecimento oficial da transubstanciação do conhecimento profano em conhecimento sagrado".

Após a leitura de "Campo intelectual e projeto criador" (Le temps modernes, 1966) avancei, em 1974, para A economia das trocas simbólicas. Lá encontra-se "O mercado dos bens simbólicos”, versão ampliada e sofisticada (1970) do artigo que saiu na revista de Sartre, inclusive com a mesma epígrafe, de Proust (Sodome et Gomorrhe): "as teorias e as escolas, como os micróbios e os glóbulos, se devoram reciprocamente e asseguram por sua luta a continuidade da vida". Ainda é leitura obrigatória "A força do sentido", introdução escrita por Miceli (1973), que pode ser combinada com "A procura de uma sociologia da prática” (Ortiz, 1983). Depois, é mergulhar no livro para compreender os contornos gerais da obra do autor. Sugiro a apropriação da coletânea em 3 blocos: I. Condição de classe e posição de classe, Uma interpretação da teoria da religião de Max Weber, Modos de produção e modos de percepção artísticos e Estrutura, babitus e prática; II. Sistemas de ensino e sistema de pensamento, A 
excelência e os valores do sistema de ensino francês e Reprodução, cultura e reprodução social; III. O mercado de bens simbólicos, Gênese e estrutura do campo religioso e Campo do poder, campo intelectual e habitus de classe. No texto dedicado ao campo religioso, abrem-se perspectivas metodológicas que são constantemente retomadas por Bourdieu, em especial quando escreve que as principais teorias da religião podem, todas elas, "ser situadas em relação a três posições simbolizadas pelos nomes de Marx, Weber e Durkheim” (1974, p. 27). ${ }^{6}$

Simultaneamente, li um pequeno livro de Bourdieu \& Passeron (Mitosociologia: Contributi a una sociologia del campo intelletuale, 1971), com dois ensaios provocativos ("Sociologia e Filosofia na França desde 1945. Morte e ressurreição da Filosofia sem sujeito" e "Sociologia da mitologia e mitologia da sociologia"), que me abriu em definitivo a mente para incorporar o autor em meu regime de leituras, tornando-se impossível percorrer outros textos sem ter como referência a maneira como Bourdieu desenvolvia (ou desenvolveria) seu métier de sociólogo. Enquanto surgiam outros livros e a revista Actes de la Recherche en Sciences Sociales deslanchava, Miceli (A noite da madrinha e Intelectuais e classe dirigente no Brasil: 1920-1945) e Durand (Arte, privilégio e distinção: 1855-1985) também avançavam em suas pesquisas.

Com exceção de Sociologia de l'Algérie (1958), apenas em fins dos anos 70 li seus trabalhos sobre esse país da África: Le déracinement. La crise de l'agriculture traditionnelle en Algérie (com A. Sayad, 1964), Travail et travailleurs en Algérie (com A. Darbel, J.-P. Rivet e C. Seibel, 1964) e Algérie 60 (1977). Antes, em 1974, tomei contato com Un art moyen (com L. Boltanski, R. Castel e J.-C. Chamboredon, 1965) e L'amour de l'art (com A. Darbel, 1965) - Le métier de sociologue (com Passeron e Chamboredon, 1968) havia lido em 1973.

Dentre as quase duas dezenas de livros escritos além dos citados, os de maior impacto foram, talvez, La distinction. Critique sociale $d u$ jugement (1979), Homo academicus (1984), La noblesse d'État. Grandes écoles et esprit de corps (1989), As regras da arte. Gênese e estrutura do campo literário (1992), Réponses. Por une anthropologie réflexive (com L. Wacquant, 1992) e A miséria do mundo (1993) - sem falar nas Meditações pascalianas (1997) e em outros livros de grande apelo junto ao grande público, em particular os editados na coleção Raisons d'Agir (Sobre a televisão, 1996; Contrafogos: Táticas para enfrentar a invasão neoliberal, 1998; e Contrafogos 2: Por um movimento social europeu, 2001). 
Olhando o percurso intelectual de Bourdieu durante 45 anos, creio ser possível concordar com Wacquant, na introdução a Réponses: "se alguma característica distingue Bourdieu no panorama da teoria social contemporânea, é sua constante preocupação pela reflexibilidade" - ou, como escreve Alicia Gutiérrez no prólogo de coletânea editada na Argentina, o autor explora ao máximo "os condicionantes sociais dos produtores de conhecimento social” (2000, p. 12). A preocupação com a reflexibilidade ocorre num quadro epistemológico em que as falsas fronteiras do conhecimento são superadas, e antropologia, economia, educação, filosofia, história, geografia, lingüística, literatura, matemática, política, psicanálise, religião, sociologia, cinema, teatro, música, fotografia, artes plásticas, arquitetura, aparecem em seus trabalhos. Seguindo certa tradição francesa de intelectuais engajados que remonta a Zola, a Voltaire, a Sartre, Bourdieu, ao contrário, não pretendeu intervir em nome de uma moral universal; engajou-se no combate em nome de seu saber de pesquisador. "Ele havia tomado de empréstimo a Michel Foucault a teoria do 'intelectual específico' que, em oposição ao 'intelectual universal', não se proclama 'mestre da verdade e da justiça', mas detentor de alguns conhecimentos em um determinado domínio" (Le Monde, 2002). Talvez não seja por outra razão que no filme La sociologie est un sport de combat (dirigido por Pierre Carles, 2001), quando Bourdieu se vê duramente questionado em debate no auditório de um banlieue parisiense, um dos presentes na platéia toma a sua defesa e afirma: "C'est Bourdieu, pas Dieu!”.

\section{Recebido e aprovado em abril de 2002.}

\section{Notas}

1. Classe preparatória literária à Escola Normal Superior. Em Meditações pascalianas são evocados "os ritos de instituição capazes de produzir a parcela de convicção íntima e de adesão inspirada que, por volta dos anos 50, era condição de ingresso na tribo dos filósofos (Pósescrito 1: Confissões impessoais, p. 45).

2. O percurso intelectual de Bourdieu aparece em vários textos, destacando-se, entre outros: Catani (2001a); Catani, Catani e Pereira (2001b; 2001c), Miceli (1999; 2002); Pinto (2000); Bonnewitz $(1998 ; 2002)$. Assim, não será detalhado aqui o início de carreira no Liceu de Moulins (1954-55), o serviço militar na Argélia (1955-58), o exercício didático como professor assistente na Faculdade de Letras de Argel (1958-60), bem como sua carreira posterior: professor na Faculdade de Letras de Lille (1961-64) e, a partir de 1964, diretor de estudos na École des Hautes Études en Sciences Sociales, tornando-se diretor do Centre de Sociologie de l'Éducation et de la Culture (Paris). Em 1975 criou a revista Actes de la Recherce en Sciences Sociales e, em 1981, tornou-se titular da Cadeira de Sociologia do Collège de France. 
3. Em outro texto, Prado Jr (1986, p. 111-112), comentando as diferenças entre as culturas européia e brasileira, fala que no Brasil estamos acostumados a uma espécie de "à vontade" com as idéias. Segundo ele, "os europeus 'caem do cavalo' de maneira muito mais dura que nós brasileiros". Uma leitura dos filósofos e dos teóricos da educação e da cultura européia mais recentes, no seu entender, indica isso. "Eles descobrem no temor e no terror que a cultura é uma questão de palavras que escondem pequenos privilégios sociais. E chegam até a exagerar nessa direção. Refiro-me aí aos textos dos teóricos da educação (Bourdieu etc.) que chegam a falar bobagens a respeito da cultura e da educação, porque, ao descobrirem o caráter discriminatório da educação, eles dizem que a educação não é nada mais do que a reprodução da diferença. O fato é que a cultura européia é tão consolidada que a descoberta do caráter arbitrário é uma tragédia para o europeu e um fenômeno tardio, enquanto que nós estávamos familiarizados com isso ( )".

4. Ver Catani (2002), de onde se extraíram algumas passagens aqui trabalhadas.

5. Para Lechte (1996, p. 72), o habitus vem a ser "uma espécie de gramática das ações que serve para diferenciar uma classe (por exemplo, a dominante) de outra (por exemplo, a dominada) no terreno social. Em La distinction, Bourdieu se refere ao babitus como um sistema de esquemas para a elaboração de práticas concretas. Assim, se o 'bom gosto' implica que o catedrático universitário vai preferir claramente o Cravo bem temperado de Bach, enquanto os trabalhadores manuais e os funcionários de classe média preferirão $O$ Danúbio azul, a validade do bom gosto se encontra menos valorizada quando se revela que o catedrático (especialmente de direito ou medicina) é, por sua vez, filho de outro catedrático que possuía uma coleção particular de arte e cuja esposa era uma boa musicista amadora. O catedrático é alguém que não apenas 'alcançou' certos êxitos no campo da educação, mas também herdou um capital cultural. É dizer que, em casos concretos, o entorno familiar pode prover um grande volume de conhecimentos, compreensão e 'gosto' que não se aprende formalmente, a não ser que se adquira de forma consciente. Um habitus específico vem à luz quando se demonstra estatisticamente que há diversas variáveis (trabalho, educação, rendas, preferências artísticas, gostos culinários, etc.) que são correlacionadas entre si. Assim, em contraste com o trabalhador manual, o catedrático de direito, normalmente, teve uma educação em colégio privado, preferirá a Bach (e, preferencialmente, a forma artística precedendo ao seu conteúdo), terá renda elevada e preferirá a cozinha simples e elegante, composta de carnes magras, fruta fresca e verduras. Esta correlação é o que, a juízo de Bourdieu, constitui uma série concreta de atitudes (neste caso, burguesa ou dominante), ou habitus".

6. Atualmente redijo trabalho que explora essa dimensão recorrente nos trabalhos de Bourdieu.

\section{Referências bibliográficas}

BONNEWITZ, Patrice. Pierre Bourdieu: Vie, oeuvre, concepts. Paris: Ellipses, 2002.

. La sociologie de Pierre Bourdieu. Paris: PUF, 1998.

BOURDIEU, Pierre. "Campo intelectual e projeto criador". In: Poulllon, Jean (Org.), Problemas do estruturalismo, Rio de Janeiro: Zahar, 1968.

. A escola conservadora: "As desigualdades frente à escola e à cultura”. In: ___. Escritos de educação, Petrópolis: Vozes, 1998. 
. J'avais 15 ans : Pierre par Bourdieu. Le Nouvel Observateur, Paris, 31 jan./6 fév. 2002, n 1943, p. 46-47.

"Gênse e estrutura do campo religioso". In: Miceli, Sergio (Org.), A economia das trocas simbólicas, São Paulo: Perspectiva, 1974.

- Meditações pascalianas. Trad. Sergio Miceli. Rio de Janeiro: Bertrand Brasil, 2001 (Pós-escrito 1: Confissões impessoais).

. O mercado de bens simbólicos. In: Miceli, Sergio (Org.), $A$ economia das trocas simbólicas, São Paulo: Perspectiva, 1974.

Que es hacer hablar a un autor? A propósito de Michel Foucault. In: _. Capital cultural, escuela y espacio social. México: Siglo Veintiuno, 1997.

- Questôes de sociologia. Trad. Jeni Vaitsman. Rio de Janeiro: Marco Zero, 1983.

BOURDIEU, Pierre; PASSERON, Jean-Claude. Les héritiers: Les étudiants et la culture. Paris: Minuit, 1964.

- Mitosociologia: Contributi a una sociologia del campo intelletuale. Bologna, 1971.

BOURDIEU, Pierre; SAINT-MARTIN, Monique de. "As categorias do juízo professoral”. In: Bourdieu, Pierre, Escritos de Educação, Petrópolis: Vozes, 1998.

BOURDIEU, Pierre; WACQUANT, Loïc. Réponses. Pour une anthropologie réflexive. Paris: Seuil, 1992.

CATANI, Afrânio Mendes. "Algumas lições da aula inaugural de Pierre Bourdieu”. In: Catani, A.M.; Martinez, P.H. (Orgs.), Sete ensaios sobre o Collège de France. 2o ed. São Paulo: Cortez, 2001a.

. Educação, violência simbólica, capitais (cultural e social) e destino. Texto apresentado no $2^{\circ}$ Colóquio Marx e Engels (Marxismo e Ciências Humanas) no IFCH-Unicamp, Centro de Estudos Marxistas (Cemarx), em novembro de 2001 (no prelo, 2002).

. Era um garoto que como eu aprendeu a ler e escrever aos anos 60. In: Fernandes, Rogério; AdÃo, Áurea (Orgs.), Leitura e escrita em Portugal e no Brasil (1500-1970). Vol. 3. Porto: Sociedade Portu- 
guesa de Ciências da Educação - Actas do $1^{\circ}$ Congresso Luso-Brasileiro da História da Educação, 1998.

. "Pierre Bourdieu e a formulação de uma teoria social que procura revelar os fundamentos ocultos da dominação". In: BRUHNS, Heloisa T.; Gutierrez, Gustavo L. (Orgs.), O corpo e o lúdico, Campinas: Autores Associados, 2000.

CATANI, Afrânio Mendes; CATANI, Denice Bárbara; PEREIRA, Gilson R. de M. As apropriações da obra de Pierre Bourdieu no campo educacional brasileiro através de periódicos da área. Revista Brasileira de Educação, Anped, maio-ago. 2001c, nº 17.

. "Pierre Bourdieu: As leituras de sua obra no campo educacional brasileiro". In: Tura, Maria de Lourdes Rangel (Org.), Sociologia para educadores, Rio de Janeiro: Quartet, 2001b.

CUNHA, Luiz Antônio. A simbólica violência da teoria. Cadernos de Pesquisa, São Paulo: Fundação Carlos Chagas, nov. 1982, nº 43, p. 55-57.

DORTIER, Jean-François. Les idées pures n’existent pás. Sciences Humaines, numéro spécial Pierre Bourdieu, Paris, 2002, p. 3-8.

DURAND, José C. Arte, privilégio e distinção. Artes plásticas, arquitetura e classe dirigente no Brasil (1855-1985). São Paulo: Perspectiva/ Edusp, 1989.

. Torcidas de nariz a Bourdieu e Passeron. Cadernos de Pesquisa, São Paulo: Fundação Carlos Chagas, nov. 1982, nº 43, p. 52-54.

GONZÁlEZ, Horacio. Lendo Benjamin. Lua nova. São Paulo: CEdec, $\mathrm{n}^{\circ} 27$.

GUTIÉRREZ, Alicia B. "La tarea y el compromiso del investigador social. Notas sobre Pierre Bourdieu”. In: Bourdieu, P. Intelectuales, política y poder, 2a ed., Buenos Aires: Eudeba, 2000.

LE MONDE. Le pouvoir des mots (Éditorial). Paris, 26 jan. 2002.

LECHTE, John. "Bourdieu”. In: . (Org.). Cincuenta pensadores contemporáneos esenciales. Madrid: Ediciones Cátedra, 1996.

MICELI, Sergio. Entenda a sua época: Sociologia. Folba de S. Paulo, Caderno Mais!, 13 abr. 1997. 
. "A força do sentido". In: Bourdieu, Pierre, $A$ economia das trocas simbólicas, São Paulo: Perspectiva, 1974.

. Intelectuais e classe dirigente no Brasil. São Paulo/Rio de Janeiro: Difel, 1979.

. Um intelectual do sentido. Folha de S. Paulo, Caderno Mais!, 7 fev. 1999.

- A noite da madrinha. São Paulo: Perspectiva, 1972.

. Uma revolução simbólica. Folba de S. Paulo, 27 jan. 2002.

NOGUEIRA, Maria Alice. Apresentação ao artigo A escola conservadora: as desigualdades frente à escola e à cultura, de Pierre Bourdieu. Educaşão em Revista, Belo Horizonte, dez. 1989, nª 10, p. 3-4.

NOGUEIRA, Maria Alice; CATANI, Afrânio Mendes. "Uma sociologia da produção do mundo cultural e escolar". In: Bourdieu, Pierre, Escritos de Educação (Organização, introdução e notas de Maria Alice Nogueira e Afrânio Mendes Catani), $3^{a}$ ed., Petrópolis: Vozes, 2001.

ORTIZ, Renato. "A procura de uma sociologia da prática”. In: BourDIEU, Pierre, Sociologia, São Paulo: Ática, 1983.

PINTO, Louis. Pierre Bourdien e a teoria do mundo social. Rio de Janeiro: Editora FGV, 2000.

PRADO JR., Bento. "A educação depois de 1968, ou cem anos de ilusão”. In: Chauí, M.; Tragtenberg, M.; Romano, R.; Prado Jr., B. Descaminhos da educação pós-68. São Paulo: Brasiliense, 1980, p. 930 .

. "Cruz Costa e a História das Idéias no Brasil”. In: Moraes, R.; Antunes, R.; Ferrante, V.B. (Orgs.), Inteligência brasileira, São Paulo: Brasiliense, 1968, p. 101-124.

SILVA, Tomaz Tadeu da. "Bourdieu e a educação". In: (Org.), Identidades terminais: As transformações na política da pedagogia e na pedagogia da política, Petrópolis: Vozes, 1996.

WACQUANT, Loïc. "Bourdieu in America: Notes on the transatlantic importation of social theory". In: CalHoun, Craig; Lipuma, Edward; Postone, Moishe (Orgs.), Bourdieu: Critical perspectives, Cambridge: Polity Press, 1993, p. 235-262. 